\title{
SMRN
}

\section{Social Media Toolkit}
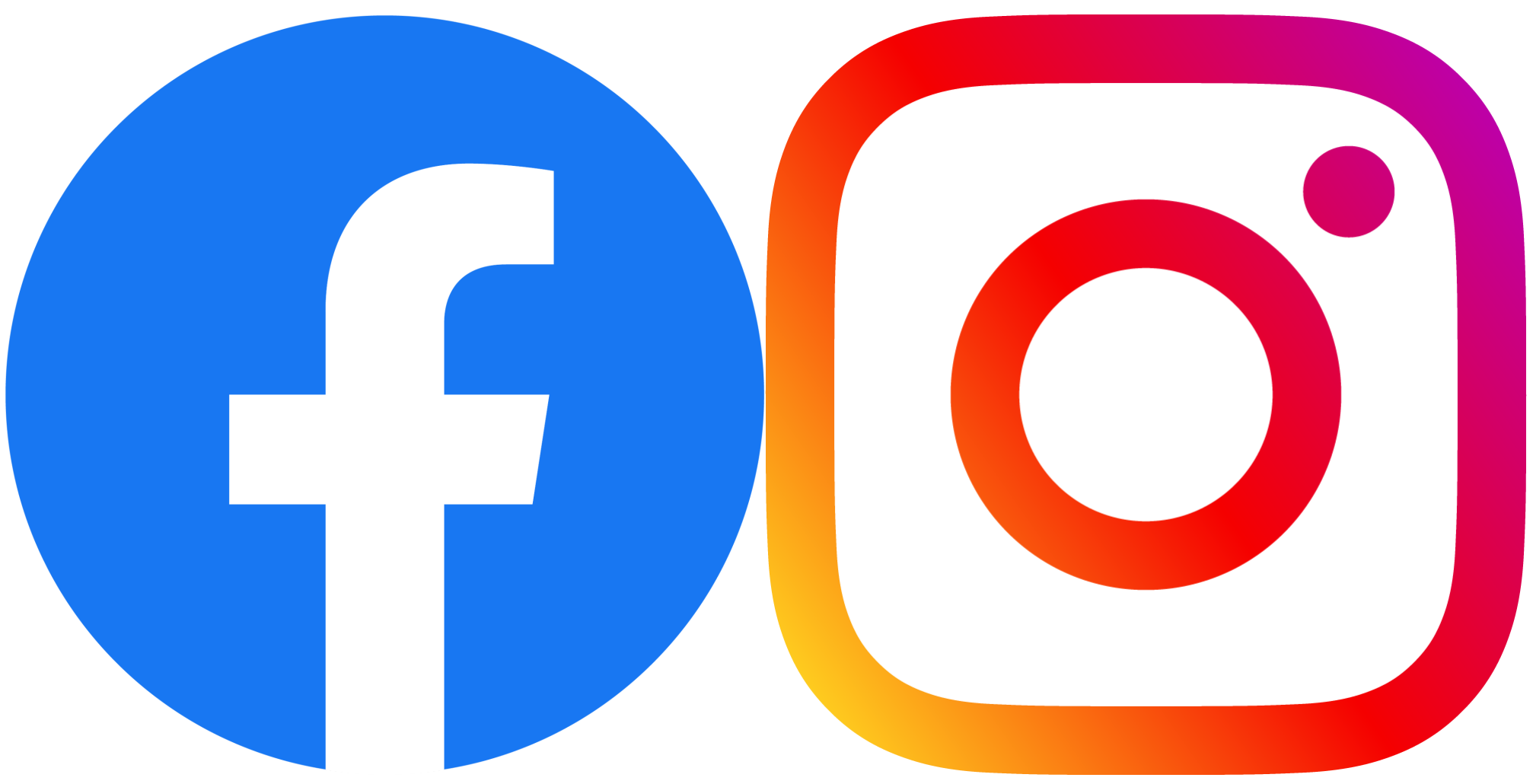

\section{Facebook and Instagram}

October 28, 2021

Shroff, A., Roulston, C. A., Ruiz, M., \& Chen, S. (2021, November 9). Social Media Research Network: Social Media Toolkit. https://doi.org/10.31234/osf.io/wr74t

The co-authors would like to acknowledge contributions of Saskia Jorgensen, B.A., Rutgers University and Jessica Schleider, Ph.D., Stony Brook University, who provided valuable feedback on a previous version of this document. 


\section{Contributors/Authors}

Akash Shroff, B.S., Department of Psychology, Stony Brook University Chantelle Roulston, B.A., Department of Psychology, Stony Brook University Marian Ruiz, B.A., Department of Psychology, Catholic University of America Sharon Chen, B.S.E., Department of Psychology, Stony Brook University

\section{Reviewers}

Saskia Jorgensen, B.A., Department of Psychology, Rutgers University Jessica Schleider, Ph.D., Department of Psychology, Stony Brook University

Please note that Facebook and Instagram guidelines are subject to change and this document is checked for accuracy based on the last update date listed on the cover page.

Thank you to everyone that helped edit and proofread our toolkit! 


\section{Table of Contents}

Executive Summary $\quad 4$

Getting Started with Instagram $\quad \mathbf{5}$

$\begin{array}{lr}\text { Post Management } & 8\end{array}$

$\begin{array}{lr}\text { Instagram Basics } & \mathbf{1 0}\end{array}$

$\begin{array}{ll}\text { Facebook Basics } & \mathbf{1 6}\end{array}$

Designing Posts for Instagram/Facebook: Canva $\quad 25$

$\begin{array}{lr}\text { Advertising using Instagram } & \mathbf{2 8}\end{array}$

$\begin{array}{ll}\text { Advertising using Facebook Ads Manager } & \mathbf{3 1}\end{array}$

SMRN Specific Suggestions $\quad \mathbf{3 4}$ 


\section{Executive Summary}

The Social Media Research Network was co-founded by Chantelle Roulston and Akash Shroff in August 2021 with the support of Dr. Jessica Schleider and the Lab for Scalable Mental Health (LSMH). Since 2018, LSMH has been recruiting adolescents and parents using social media-primarily Facebook and Instagram. As of September 2021, our social media presence has reached 1.4 million people across the world. More than 35,000 individuals have interacted with our posts and messages and more than 6,000 youth, young adults, and parents have completed our single-session interventions. We wanted to share our current success and improve our processes by forming a collaboration of psychology/adolescent development research labs.

The SMRN Social Media Toolkit is designed to consolidate social media experiences and suggestions from various labs into a useful document for others to use. This is by no means an exhaustive list of social media platforms and suggestions. We have limited the toolkit to include the use of Facebook and Instagram, owned and trademarked by Meta Platforms, Inc.. Instagram and Facebook encompass a very large audience (diverse in age, location, and race/ethnicity). The platforms have a lot of overlap and have been successful in research efforts for the authors. This toolkit outlines broad concepts of branding, post design, and post management. It also provides details, suggestions, and tips on how to create an account, gain a following, increase engagement, and more on both Facebook and Instagram. . Lastly, it details the process of using paid Facebook and Instagram advertisements for research purposes (i.e., recruiting participants).

The ultimate goal of SMRN is to increase collaboration across research groups so that we can leverage the entire network's social media presence to improve recruitment, science communication, and outreach efforts for all research groups involved. We hope this document will serve as a preliminary guide for the research groups within the network. 


\title{
Getting Started with Instagram
}

In this section, we will review one platform that is helpful with designing social media posts and share tips about the designing process. This is not an exhaustive list and many other platforms exist (Photoshop, PowerPoint, etc.).

\section{Setting up your Instagram account}

\author{
Handle, Bio, Profile Picture
}

1. Instagram Handle - Come up with a social media handle you feel captures your lab. Keep it brief (i.e. @lsmh_sbu rather than @labforscalablementalhealth).

2. Instagram Biography "Bio" - Make this succinct, and interesting. No more than a couple of sentences explaining who you are and what you do.

3. Profile Picture - The less confusing the image, the better! Canva is a great resource for creating lab logos.

\section{Starting Your Account/Initial Posts}

1. It can be helpful to use your initial posts to introduce yourself, your lab, your team, and your mission/the work that you all do.

2. Include pictures of people where possible; followers like to see the face behind the name. Example

a. This can be helpful to sprinkle throughout your feed - if you find you haven't posted any pictures or videos of lab members in a while, it can be helpful to bring the face back to the forefront of your Instagram page!

3. Take a look at accounts that have similar interests to you, make note of what aspects of their page you like and make use of those features

\section{Things to Keep in Mind}

1. Finding People to follow

a. It can be helpful to start with accounts affiliated with your university. Start by following accounts within your own department and then branch out.

b. Search by hashtags related to your interests and follow those accounts (i.e. \#mentalhealthresearch \#adolescentresearch \#psychology).

c. Follow SMRN members! (Link to SMRN database)

\section{Growing a following}

a. To gain followers, follow others! Following other pages with similar interests (i.e. other research labs) can help you, as they will often follow you back.

b. Posting consistently goes a long way towards gaining followers-people gravitate towards accounts that they can rely on for consistent content.

c. Growing a following takes patience and regular, continued posting/interaction with others/use of hashtags - even if you don't see results right away, this is the only path to gaining a following! 


\section{Tips}

1. When it comes to your handle, the fewer letters, words, and underscores the better.

2. Younger users tend to enjoy when emojis are included in an Instagram bio.

3. If your lab has a logo consider using that for the profile picture. A group lab photo is a good option as well.

Branding refers to the way that you present your lab to outside others through social media. Think of your lab as a business, and your social media accounts as your way to connect with your consumers. As with any business, it is important to have some consistency in the way that you are portraying your "product" (i.e., research findings, lab accomplishments, dissemination efforts, etc.). This section will tell you more about what and how to conceptualize and portray your "brand". For more information on the design aspects of successful branding, see the "Designing Posts" section of the toolkit.

\section{Branding/Establishing and maintaining a consistent brand}

\section{Things to Keep in Mind}

1. Consistent branding is a balance between representing who your lab is and catering to your audience. It is important to understand what kind of content your audience as a whole tends to enjoy and to then try and incorporate some of those elements into your page.

a. For example, if you're catering to adolescents around the ages of 11-16, drawing/artwork, lots of colors, and moving posts (like posts that include gifs) are really popular. Consider ways to incorporate some of those elements into your posts while still representing your lab.

\section{Questions to Reflect on}

1. What do you want your brand to be? How can you best represent this?

2. Who is your target audience? How can you create a brand designed to appeal to that group (or groups)?

3. What do you want your instagram page to portray when people look at it? How can you accomplish this?

\section{$\underline{\text { Tips }}$}

1. Post regularly. It can be helpful to have pre-set days of the week when you post (i.e. Mondays and Thursdays; 2-3 times a week minimum is ideal).

2. It can be helpful to have a recurring theme throughout your page

a. For example, your page can be consistently colorful or just one color, you can use a particular layout for each of your posts, etc. You can consistently use one font, cartoons, or do whatever you'd like. This can be really helpful for branding 
because people have an idea of what to expect and it makes your page look cleaner as a whole.

b. Even if you are only interested in recruitment using paid posts, your campaign is more likely to be successful if it is coming from an established/trustworthy account. Gaining an audience/following is important to do before starting recruitment for a research study! 


\section{Post Management}

In this section, we will review Facebook's Creator Studio and tips to manage your social media posts. It is helpful to plan your posts ahead of time and get approval from multiple members on the team, when possible. Always keep in mind that the goal is to increase engagement with your followers.

\section{Facebook's Creator Studio}

+ Creator Studio (business.facebook.com/creatorstudio) can be used to manage Facebook and Instagram posts

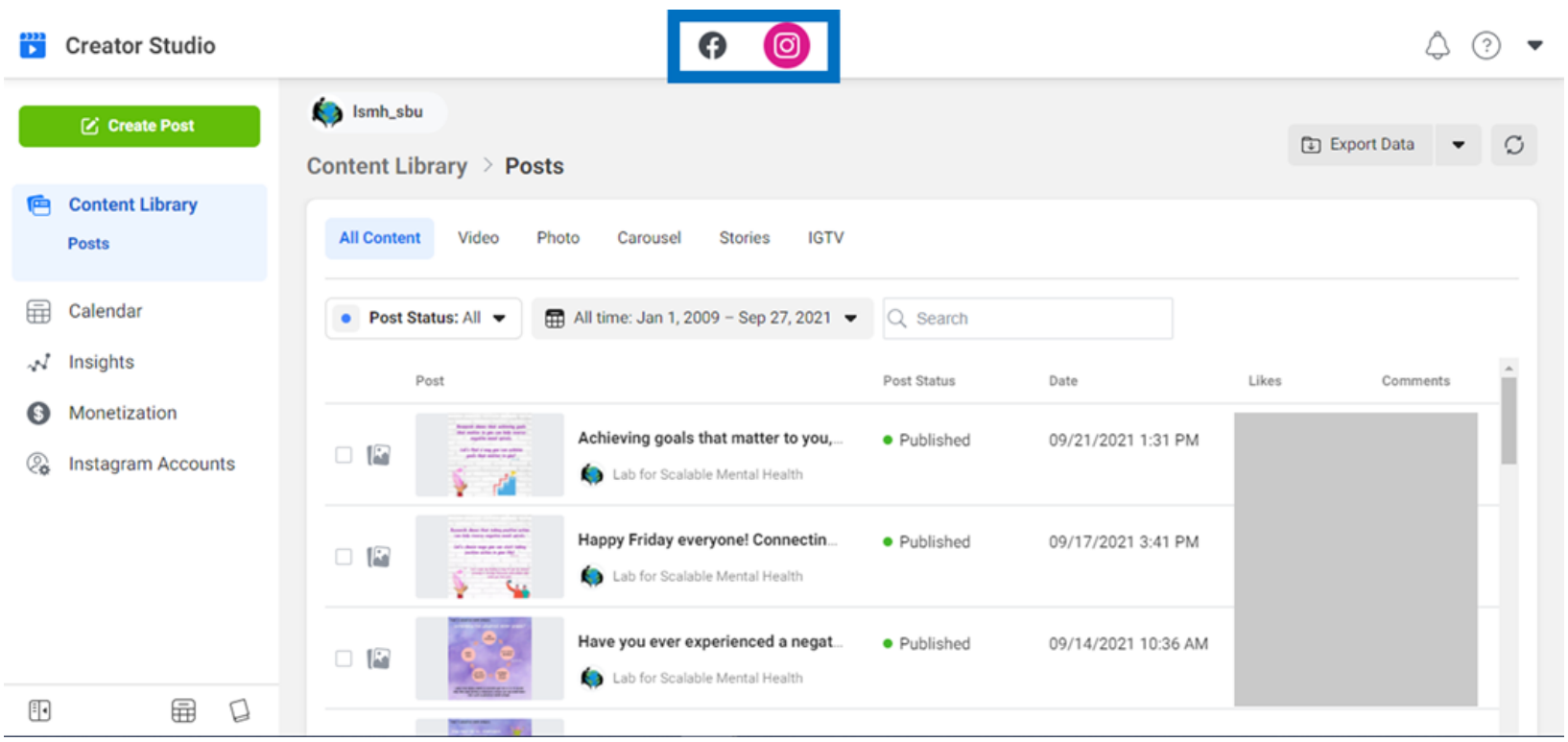

+ Create your posts using the studio platform

Creator Studio

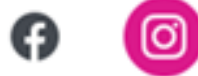

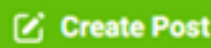

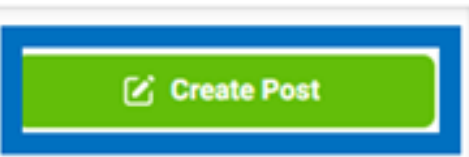

画 Content Library
(3) Ismh_sbu

Content Library > Posts

+ Schedule or publish posts immediately

+ Check out the calendar view to see when and what you are posting 


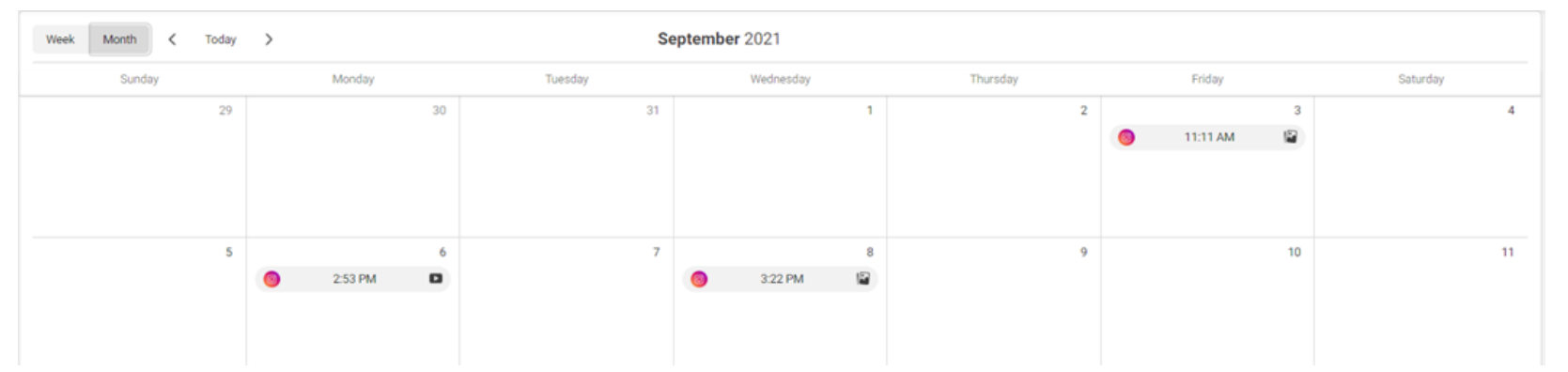

+ Look at post-specific or account-wide insights

\section{Tips}

+ When creating your posts, it can be helpful to create several at a time before posting them. This way you can see what your posts will look like all together and whether or not they complement one another.

+ Create a set number of times per week you plan to post; you can take this a step further by having particular days of the week that you post. We recommend posting 2-3 times per week to maximize engagement with your followers! This includes interacting with your followers in different ways (for example posting on your Story) not just regular posts to your page.

\section{Post Performance

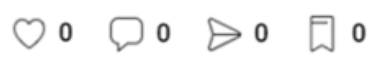

Views

0

Interactions

\section{0}

Actions taken from this post

Profile Visits

Discovery

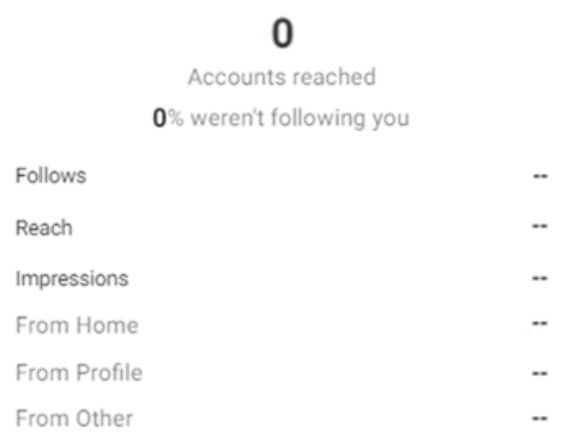




\section{Instagram Basics}

In this section, we will review the Instagram platform. We define common terms and explain helpful features. There are tips and tricks to managing your Instagram account as a research group.

\section{Features/Language of Instagram}

1. Post

a. Images or videos you post that live on your page until you delete or archive them.

b. To create a post, click on the plus button in the top right and click 'Post'.

2. Page

a. Your Instagram profile. When people search your handle, they will be brought to your page where they will be able to see your bio, profile picture, highlights, and all of your posts.
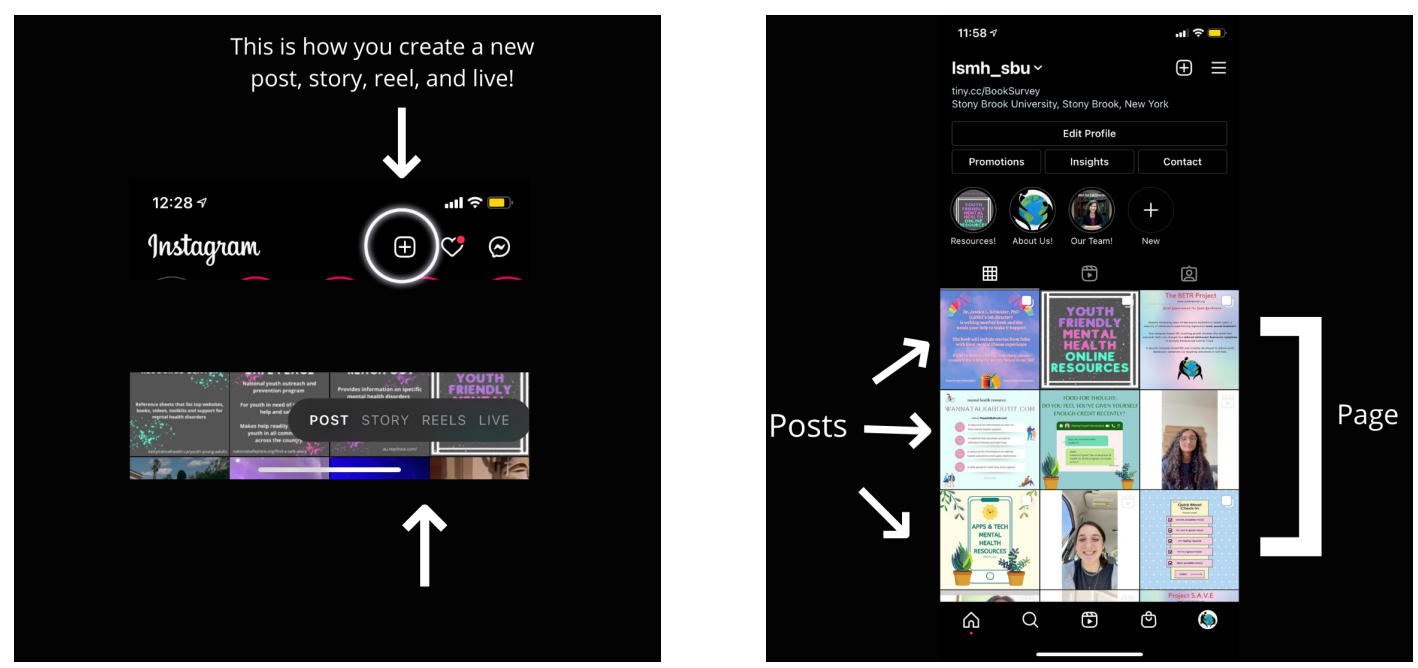

3. Feed

a. Your Instagram feed is composed of content that people you follow have posted, advertisements, and content related to any hashtags you follow.

4. Reels

a. Instagram reels are short-videos that can only be 60 seconds long.

b. To create a reel, click on the plus button in the top right and click 'Reel'.
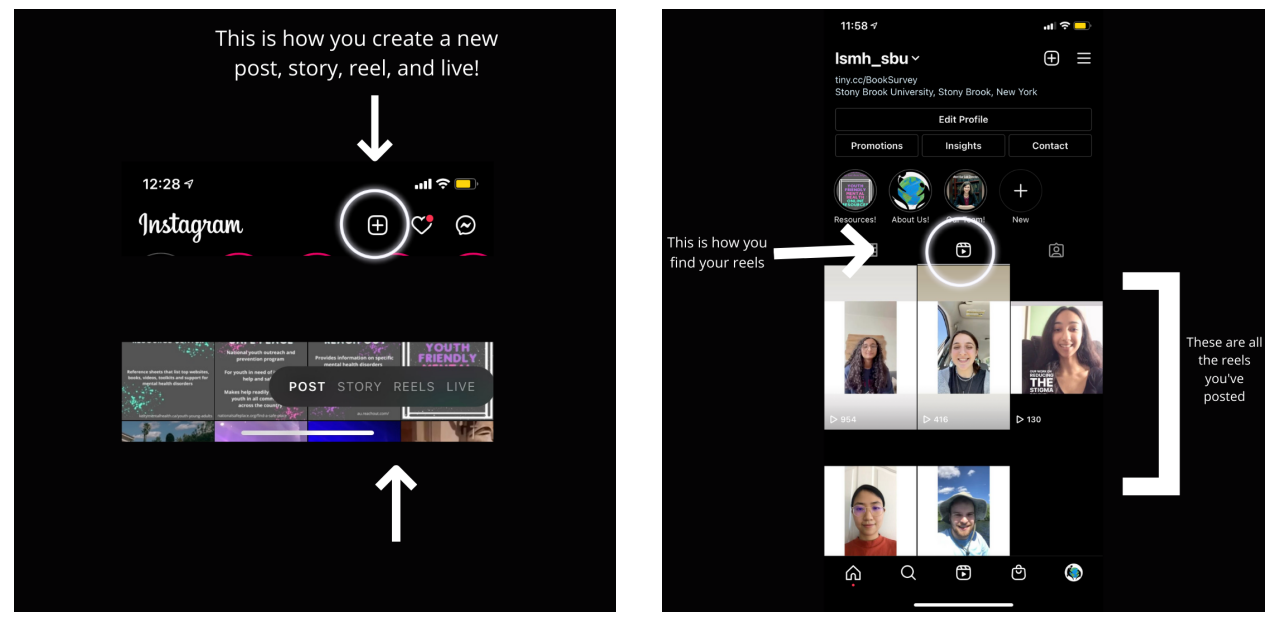
5. Story

a. You can repost other people's content or repost your own content to your Instagram story. You can also create novel content within your instagram story to post; this can be a picture or video or a series of pictures and videos. You have the option to include questions, polls, stickers, gifs and more on top of the pictures and videos you post to your story.

b. Story posts only show up for 24 hours (unless you save them to your highlights; see \#6 below)

c. To create novel content to add to your story, click the plus button in the top right and then click 'Story'.
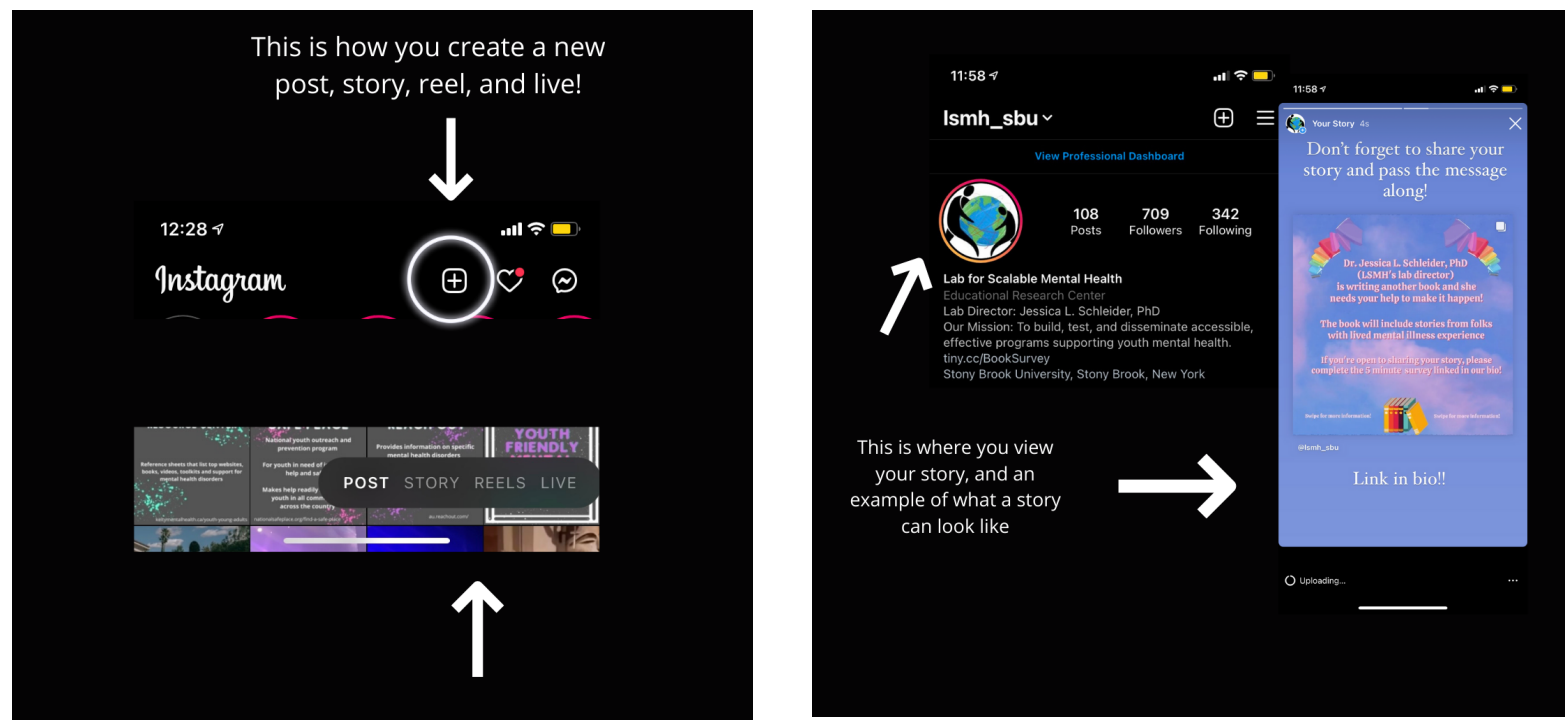

d. Posting to your story allows you to do several things, including but not limited to: promote your Instagram posts, promote others' posts, conduct polls, and receive and answer questions from followers. It is useful to post on your story rather than creating a regular post to your Instagram page when you only want the content to be visible temporarily ( 24 hours maximum).

6. Story Highlights

a. Story highlights appear beneath your instagram bio and they are collections of your previous instagram stories that you created and chose to save. For example, you can select six of your previous instagram story posts and put them together in one highlight. You can then name the highlight whatever you'd like, and you can give it a cover photo.

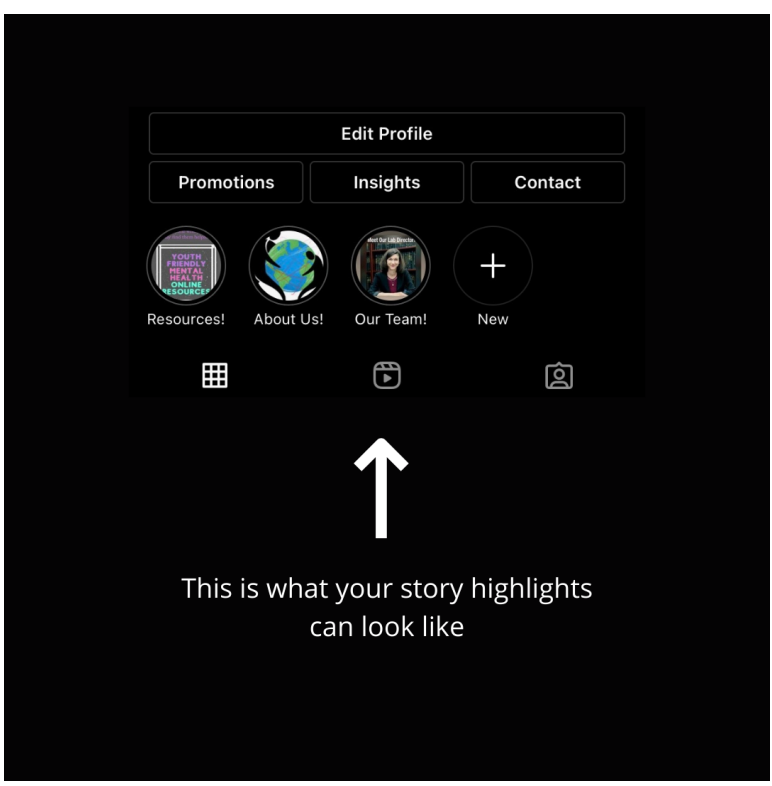


7. IGTV Video

a. IGTV allows Instagram users to create channels where they can upload videos between 15 seconds and 10 minutes long.

b. To start an Instagram Live, click on the plus button in the top right and click 'Live'.

8. Instagram Live (IG Live)

a. Instagram Live allows you to broadcast in real time to your followers. People that tune into your Instagram Live can leave likes and comments that you can respond to in real time; they can also request to join your Live. When you accept someone's request to join your Instagram Live, the two of you can broadcast live together.

b. IG Live is useful for interacting with followers for science communication events. Followers can send you messages/questions which you can respond to in real time during your live broadcast.

9. Direct Messages (DM)

a. The direct messages are where you can send and receive messages. Messages are split into Primary, General, and Requests. All of your messages will go into General until you sort them into Primary. Messages
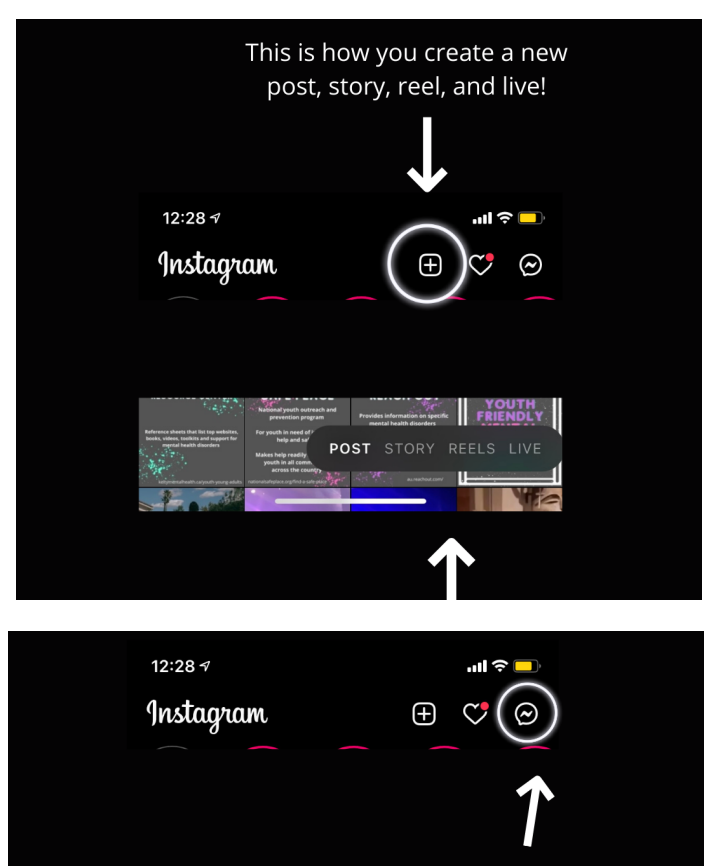

This is where your direct messages live, and these are the categories they get sorted into

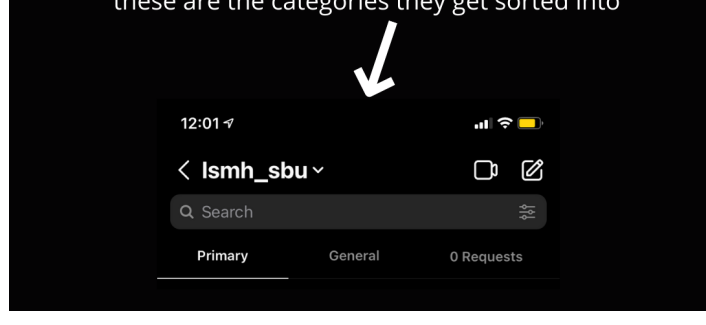
in the 'request' section typically come from people who you do not follow, specifically if you have a private account.

b. Direct Messages are useful for responding to questions from potential research participants and communicating with other labs.

10. Saving posts

a. Next to every post, you should see the save icon. You can save any posts, reels, IGTVs etc. that you see on instagram. You can also sort your saved items into groups you create.

b. To find posts you've saved, click the three horizontal lines in the top right of your Instagram page and then click on 'saved'.

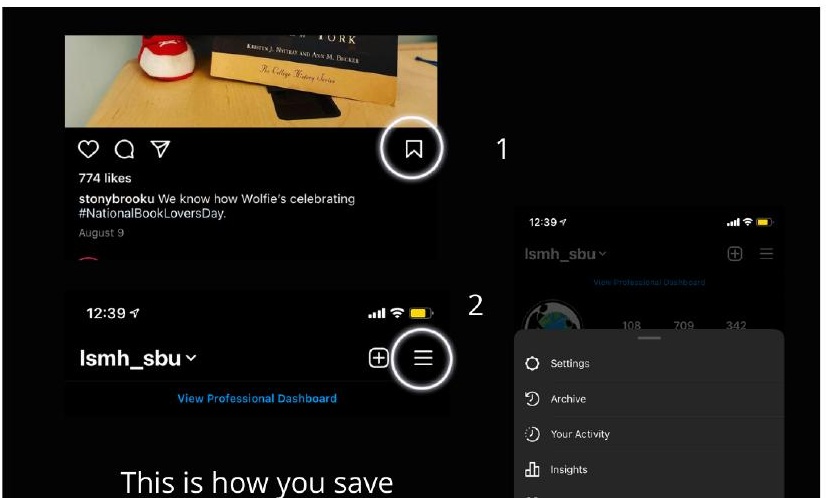


11. Archiving posts

a. When you click on the three dots in the top right of any content you post, you will see the option to archive your post.

b. To find posts you've archived, click the three horizontal lines in the top right of your Instagram page and then click on 'archive'.

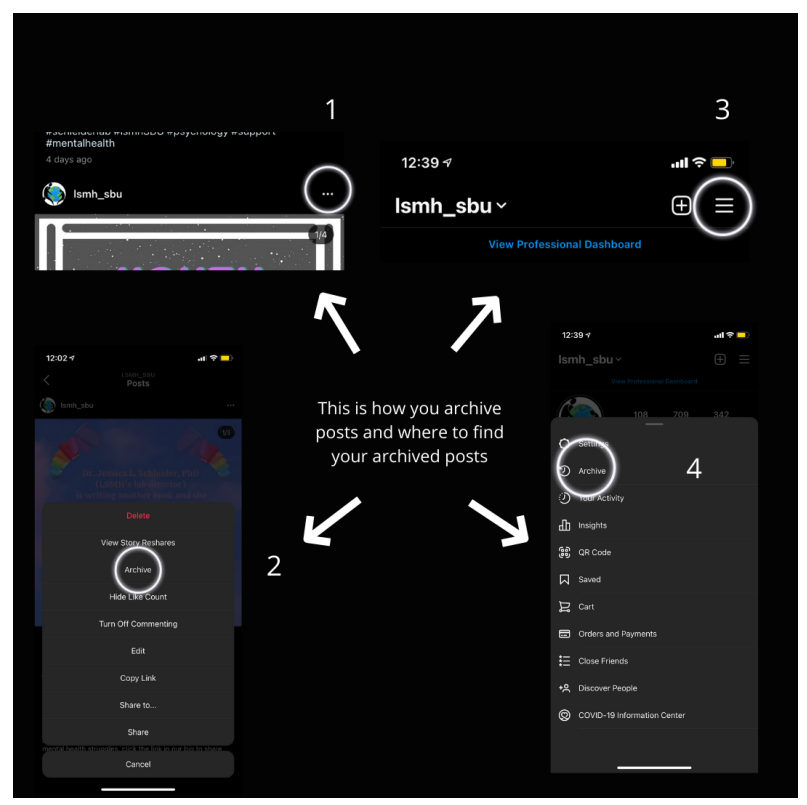

12. Hashtags

a. Hashtags are words or phrases preceded by the pound/hashtag symbol (\#). Hashtags cannot include symbols (i.e. !, \&) nor can they include spaces between the words.

b. You can follow hashtags. To follow a hashtag, type in the hashtag in the search bar, click on it when it pops up, then click follow.

c. Examples of hashtags: \#research, \#mentalhealth \#socialmediaresearchnetwork

13. Turn off commenting

a. To turn off comments under your posts, click on the three dots in the top right of your post and then click 'turn off commenting'.

14. Hide Like Count

a. To ensure people cannot see how many likes you get on a post, click on the three dots in the top right of your post and then click 'turn off commenting'.

15. Sharing Posts

a. To share a post/repost something to your instagram story (including your

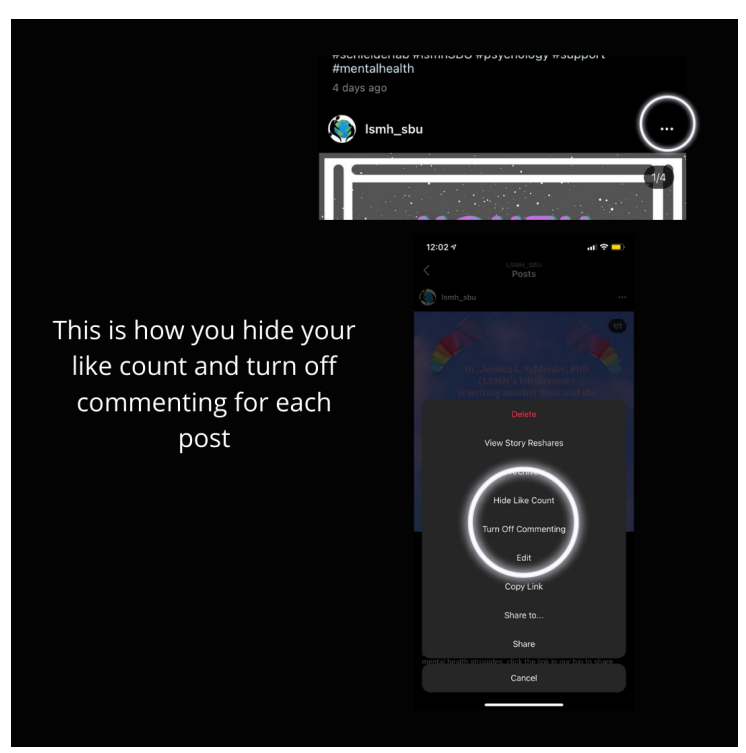


own), click on the three dots in the top right of the post and then click 'share'.

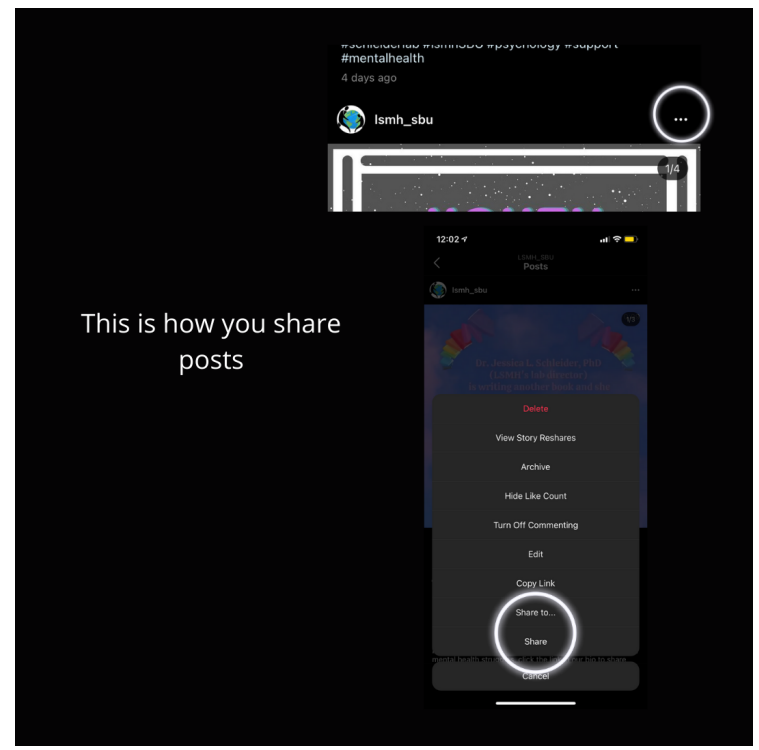

16. Explore Page

a. The explore page is composed of random posts that Instagram thinks you will like.

b. You can get to your explore page by clicking on the magnifying glass on the bottom of your screen. This is also where you can find the search bar to look for different accounts. The search bar is located at the top of your screen when you are on the explore page.

\section{Tips for using different Instagram features}

1. Post/Page

a. You can organize your posts on your page to coordinate with one another so there is a common theme that is evident just by looking at your page as a whole.

2. Reel

a. It can be helpful to use Reels instead of Posts when you want to post a video. This way, when you repost the Reel to your Story the video will play automatically and people can see the content right away.

3. Story

a. Use your story to be interactive - ask questions, post polls, invite people to ask you questions etc. Really try to have fun with your story and use it as a way to reach out to your followers; this will be more interactive than your Instagram page itself.

4. Story Highlights

a. Use your Highlights to tell a story. Incorporate the posts you want people to see the most; this way, they get all of the important information you want them to have without having to scroll throughout your entire page.

5. Hashtags 
a. Having a lab specific hashtag can be really helpful, that way certain posts are in a centralized location and it can be easy for your followers to see relevant content all at once.

6. Saved

a. It is incredibly helpful to create folders for your saved items so they don't get lost/jumbled up in everything that you save.

b. Save posts that you like and would like to imitate/take elements. This way you'll always have a place to look when you need inspiration! 


\section{Facebook Basics}

In this section, we will review one platform that is helpful with designing social media posts and share tips about the designing process. This is not an exhaustive list and many other platforms exist (Photoshop, PowerPoint, etc.).

When creating a new Facebook page, you will need to use an individual's personal Facebook account. Once the page is created, the owner of the page can add other individuals to the page to help manage it.

1. Pages $>$ Create New Page

a. Add Page Name, Category, Description. Then click on the "Create Page" button once you're done.

b. Note: you will need to search for the page you just made. It will not show up in "My Pages"
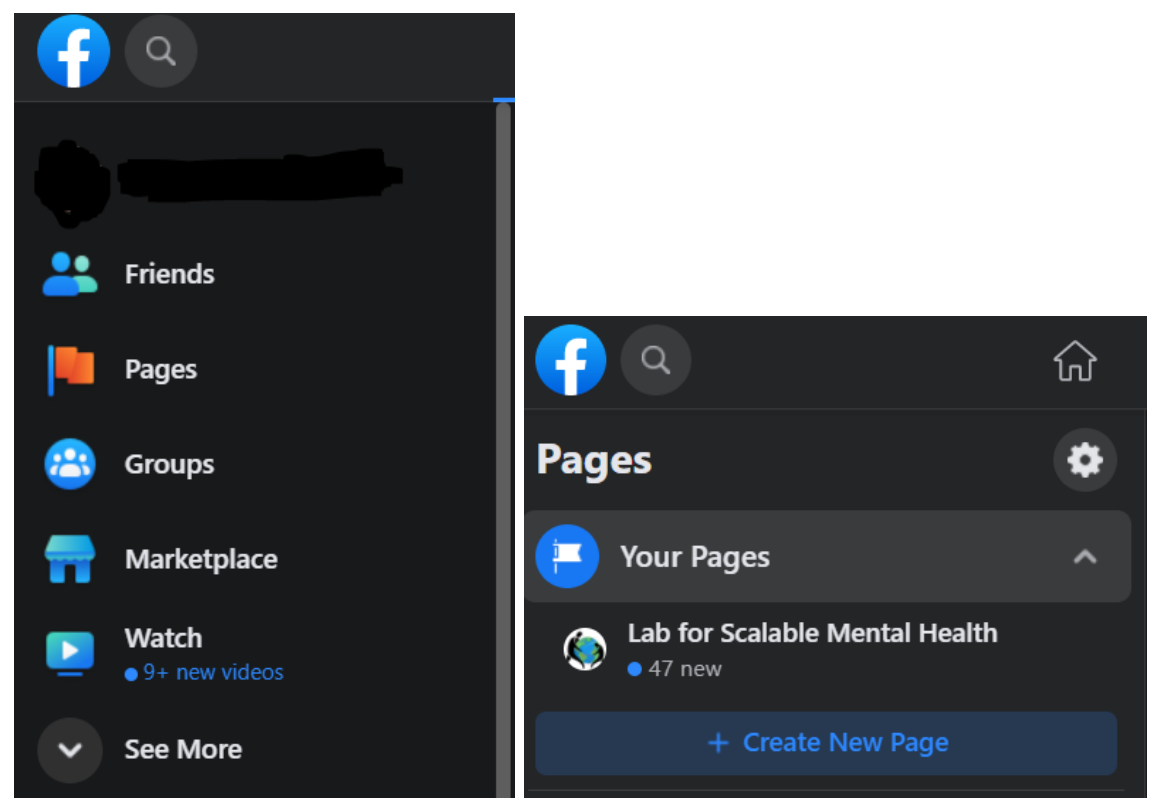

c. Example set up: 


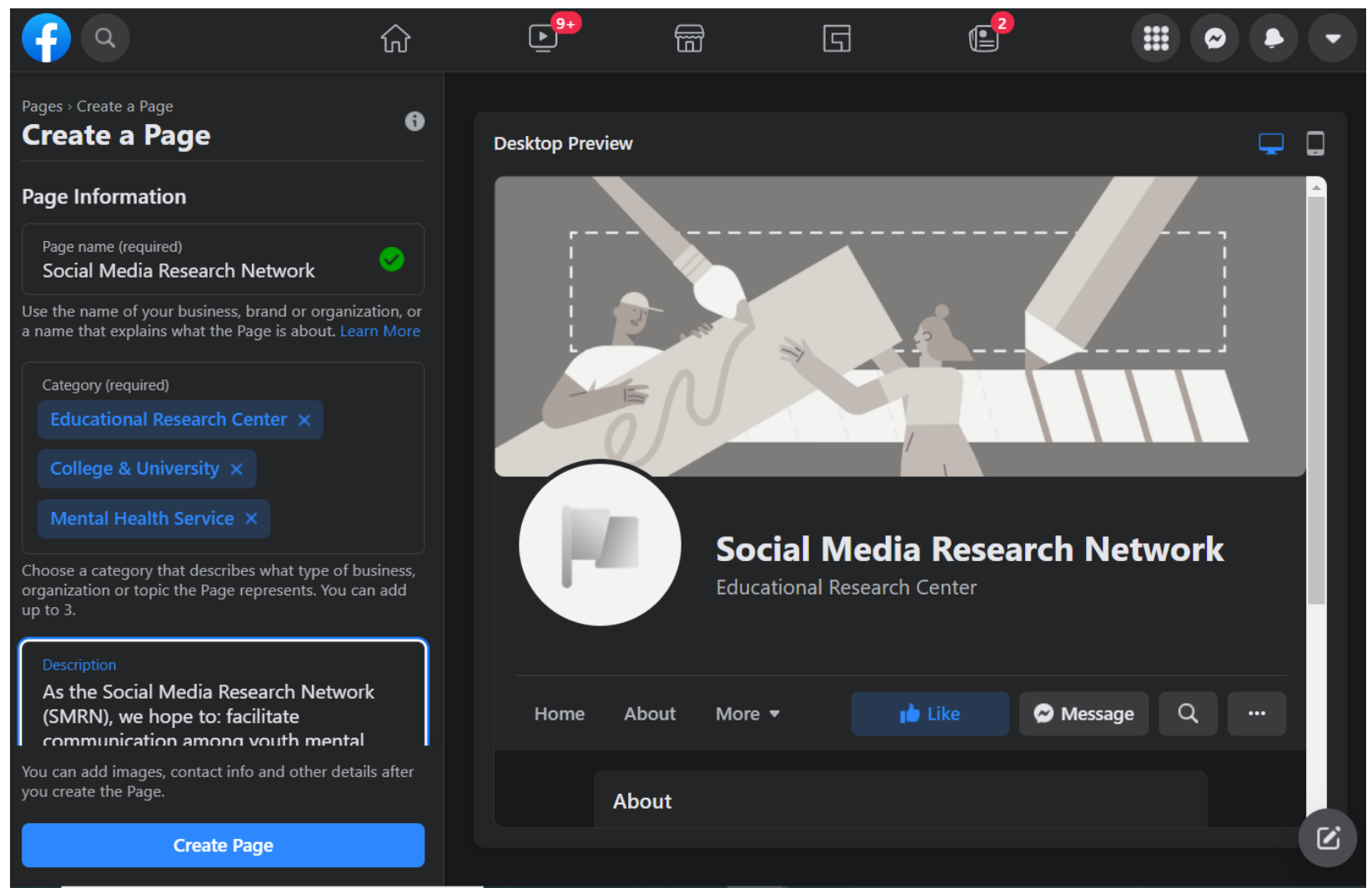

2. Update your page's handle (Username)

a. Click on "Create @Username" to create your page's handle. Alphanumeric characters only; at least 5 characters.

b. Makes it easier for others to find your page via the shorthand name 


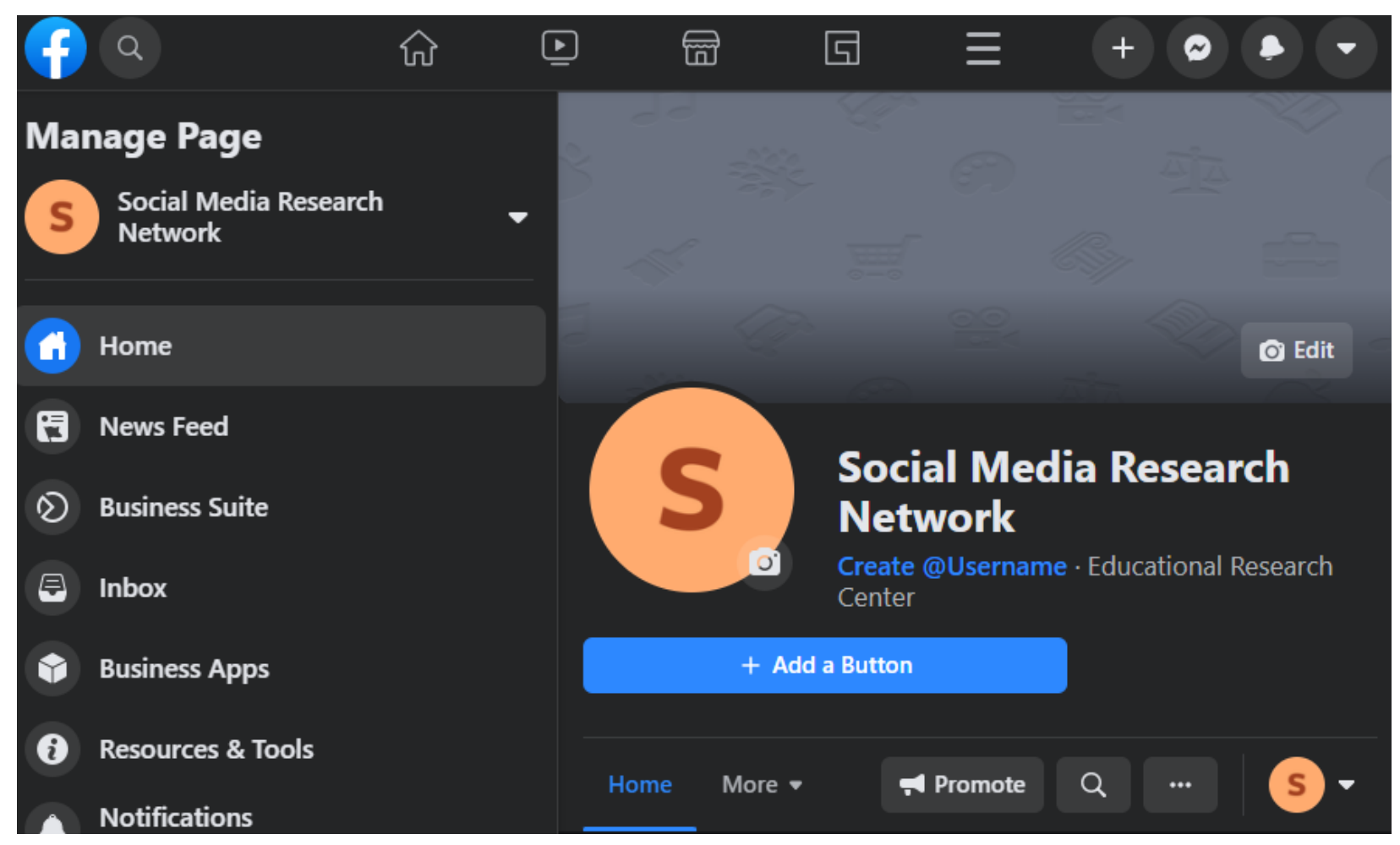

3. Add additional information

a. Establish Your Page's Identity

i. Add profile picture

ii. Add cover photo

b. Provide Info and Preferences

i. Website

ii. Location info

iii. Business hours

iv. Phone number

c. Introduce Your Page

i. Invite personal friends/colleagues to like your new page

ii. Create a welcome post

4. Using Facebook insights 


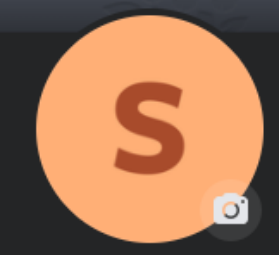

Home Groups

$\checkmark$ Promote

+ Add a Button Network

@SMRN2021·Educational Research Center

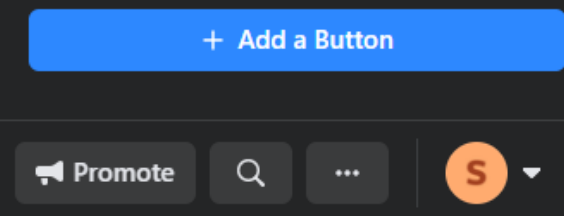

Start Selling From Your Page in a Few Steps

It only takes a few minutes to set up your shop. Just enter your business details, add the products you'd like to sell and customize your shop's home page to fit your brand.

\section{Get Started Learn More}

\section{Set Your Page up for Success}

Finish setting up your Page so people on Facebook know you're a credible business.

3 of 13 steps completed

$\hookrightarrow \square$

2 steps left

Establish Your Page's Identity

6 steps left

Provide Info and Preferences

2 steps left

Introduce Your Page

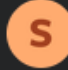

Create Post

[i] Photo/Video

N Get Messages

○) Feeling/Activity

\section{Invite Friends to Like Your Page}

More people might see your posts in News Feed

if your friends like your Page and share posts.

Facebook Insights can help you see how many people you have reached, how many post engagements you received, and how many new page likes you received recently. 


\section{Insights}

Last 28 days : Aug 12 - Sep 8 -

People Reached

0

Post Engagements

0

Page Likes

$\mathbf{0}$

Finally, you can choose how to interact with the page and posts. You can post/interact as the page or use your personal Facebook account.

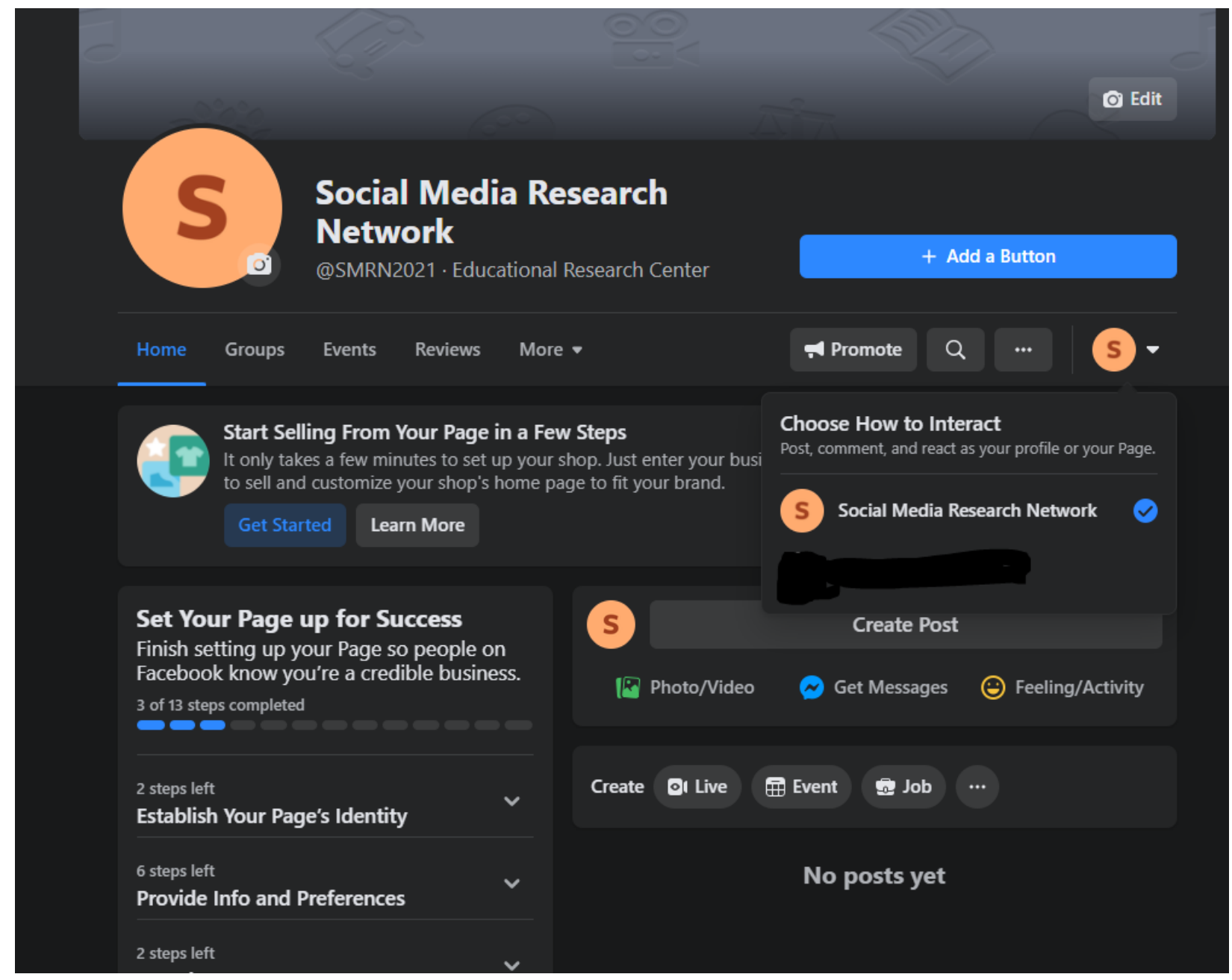


5. Adding administrators to your Page

a. Scroll to the bottom of the left-hand toolbar to "Settings"

\section{Manage Page \\ S Social Media Research \\ Network \\ (2) Business Suite \\ Inbox \\ 安 Publishing Tools}

(1) Home

i: News Feed

() Podcasts

(1) Business Apps

(i) Resources \& Tools

e. Manage Jobs

Q Notifications 02 new

N Insights

Ad Center

○ Page Quality 
b. In settings, select "Page Roles"

Social Media Research Network > Page Settings

Page Settings

Q Search Page Settings

General

Q Messaging

Page Info

H Templates and Tabs

Event Ticketing

8 Notifications

( Advanced Messaging

9. Page Roles

g. People and Other Pages

g. Preferred Page Audience

of Issue, Electoral or Political Ads

* Ad Limits

(3) Branded Content

(0) Instagram

c. Type in a name/email address to add that individual

d. Select their role (e.g. Admin, Editor, Moderator, Advertiser, Analyst)

i. Admin: have full permissions to make changes to the Page

ii. Editor: can publish content and send Messenger messages as the page, respond to/delete comments, etc.

iii. Moderator: can send Messenger messages as the page, create ads via Facebook and Instagram, see comments, view insights, respond to Instagram direct messages

iv. Advertiser: can create ads via Facebook and Instagram, see posts, view insights 
v. Analyst: can see which admin created a post or comment and view insights

\section{Page Roles}

Everyone who works on your Page can have a different role depending on what they need to work on. Learn More

\section{Sections}

Assign a New Page Role

Jump to Section

Existing Page Roles

Assign a New Page Role

Can publish content and send Messenger messages as the Page, respond to and delete comments on the Page, create ads comment, post from Instagram to Facebook, and view insights. If an Instagram account is connected to the Page, they can $\mathrm{r}$ comments, send Direct messages, sync business contact info and create ads.

who created a post or

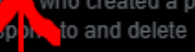

\section{Existing Page Roles}

\section{Admin}

Can manage all aspects of the Page. They can publish and send Messenger messages as the Page, respond to and delete comments on the Page, post from Instagram to Facebook, create ads, see who created a post or comment, view insights, and assign Page roles. If an Instagram account is connected to the Page, they can respond to and delete comments, send Direct messages, sync business contact info and create ads.

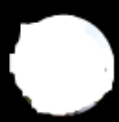

6. Connect your group's Instagram account via: Page Settings $>$ Instagram > Connect Account 
Connect to Instagram

Get additional features to reach more of your community.

Connect your Facebook Page to an Instagram account. Learn More

Depending on their access to your Facebook Page and Instagram account, people may help manage things on both like

E Content, ads and insights

Q) Messages and comments

\{0्్ Settings and permissions

Happy posting! 


\section{Designing Posts for Instagram/Facebook: Canva}

In this section, we will review one platform, Canva, that is helpful with designing social media posts and share tips about the designing process. This is not an exhaustive list and many other platforms exist (Photoshop, PowerPoint, etc.), however many find Canva to be especially user-friendly.

\section{Using Canva}

a. Go to Canva.com (login/create an account as needed)

i. Keep in mind there are some features that cost money. If you are interested in purchasing Canva Pro, you can see pricing information here. That being said, plenty can be done using the free version. :)

b. Create a new design. Here, you will be able to select what kind of content you would like to create (e.g., Instagram post, Instagram story, Facebook post, or even TikTok videos). You can pick from existing templates created by artists/designers or you can start from scratch once you select the type of design you wish to create.

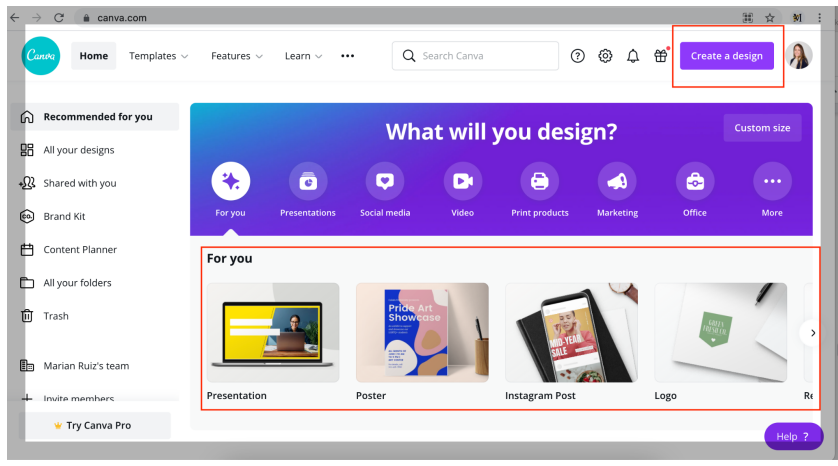

c. Pick a template and edit accordingly.

i. The element feature will allow you to add things like graphs, tables, stickers, etc ...

ii. The upload feature will enable you to upload things and add them to your flyer (e.g., uploading a logo)

iii. The text feature allows you to edit your text (e.g., change the font, spacing, etc...)

iv. The background feature allows you to change the background. You can also add an image if you want a specific background

C 1 canva.com/design/DAErlHO9qw8/W67EINAm7I_F3DDHrxosgw/edit

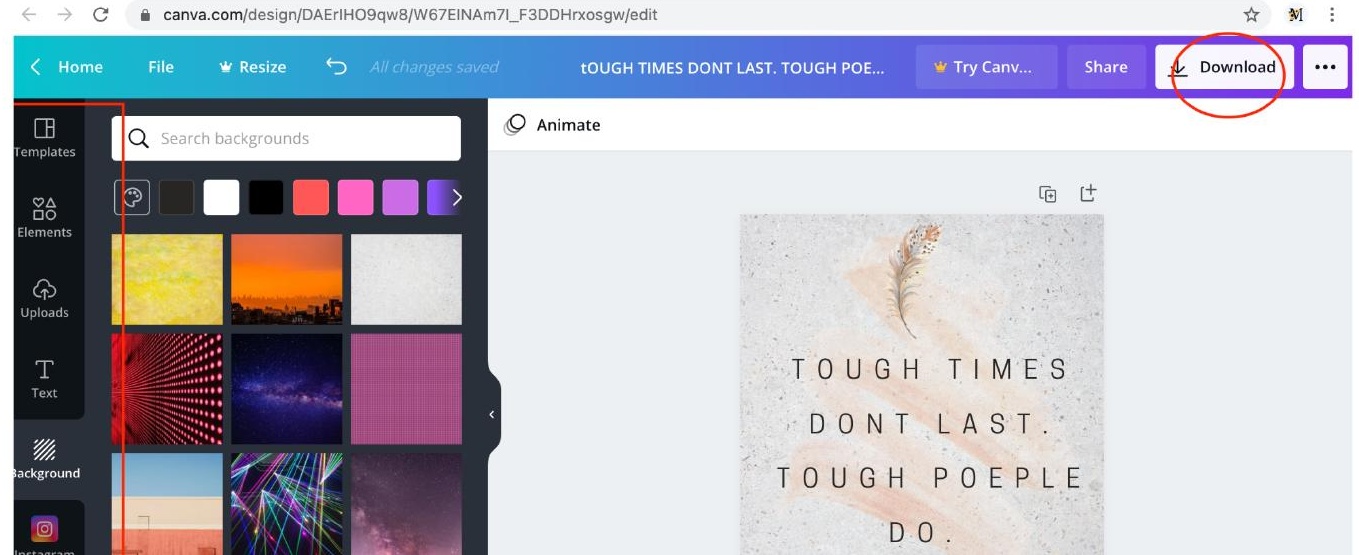


d. Once you're done editing, hit "Download," and you can download a $\mathrm{pdf} / \mathrm{jpg} / \mathrm{mp} 4 / \mathrm{etc}$. copy of your post (depending on the size/shape/content of the post)

e. The home button will take you to the landing page, where you can keep track of the posts you've created. All posts will automatically stay under "your designs." This enables you to come back to a post and continue editing. You can also share the post with someone if you wish to collaborate.

i. It can also help to have your lab members share posts they create with you so you have all lab-related posts accessible on one central account.

f. Every design will allow you to create a copy in case you wish to have a working draft

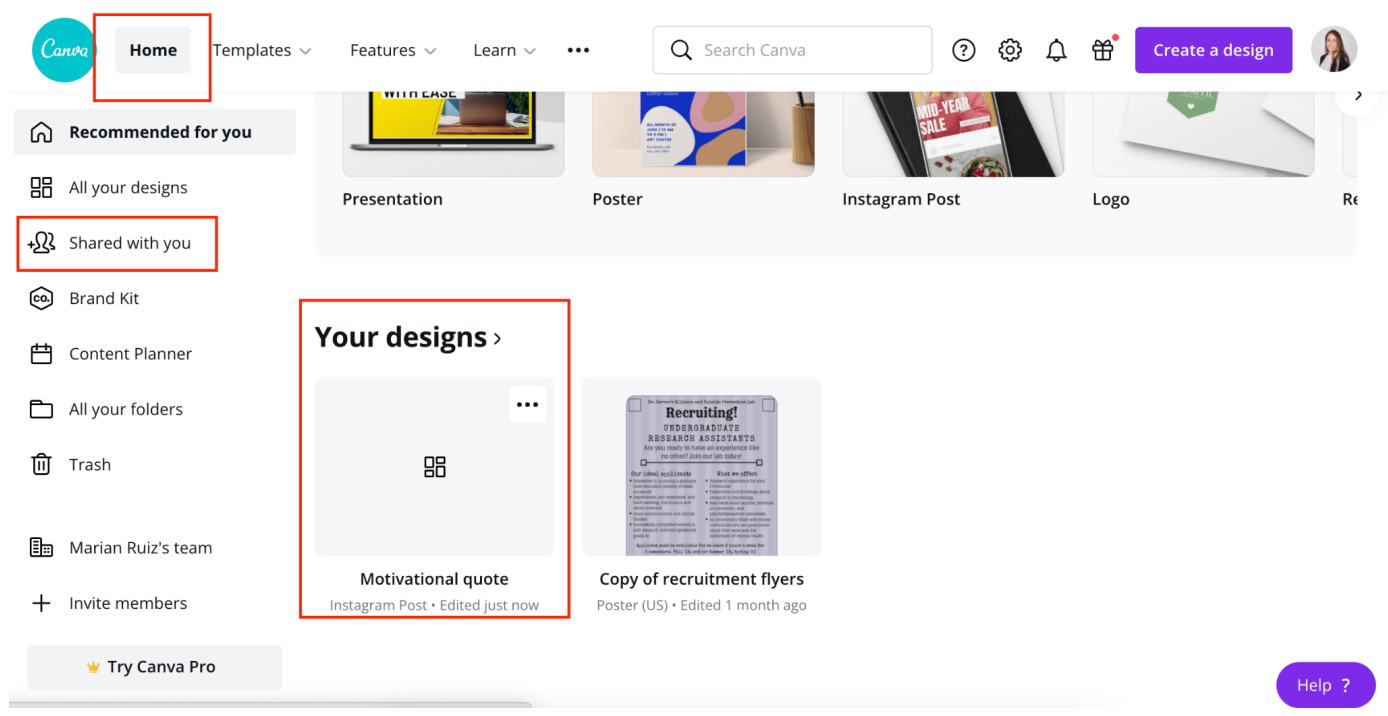

\section{Tips for designing a post}

a. Color!! Choosing the right color is essential not only to the aesthetic value of your post but also the emotional impact that you wish to create.

i. Colors convey emotions (see below)

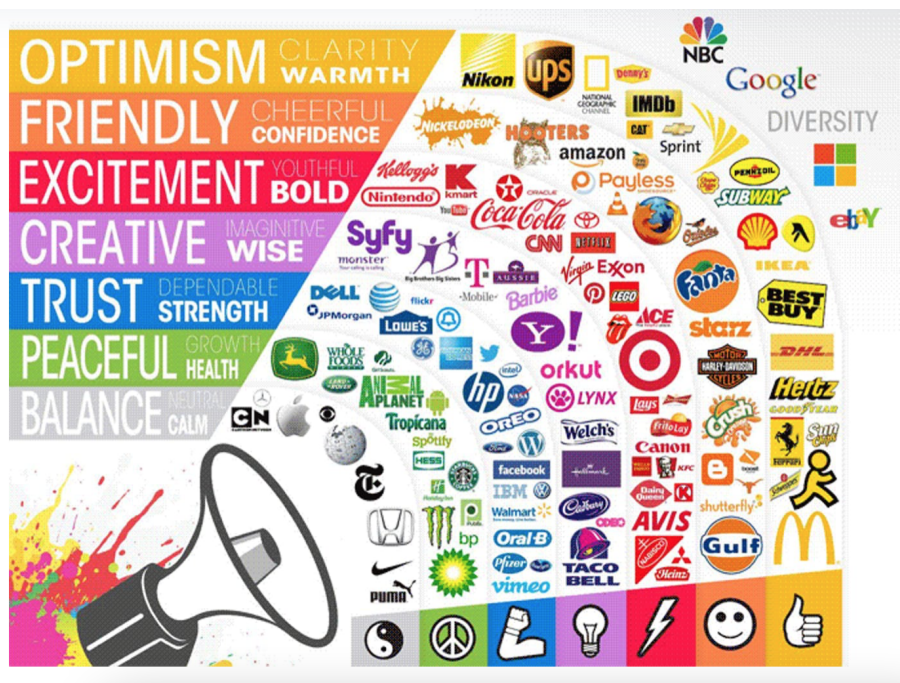


ii. Research shows that while a large majority of consumers prefer color patterns with similar hues (i.e., analogous color combinations), they also respond well to palettes with a highly contrasting accent color (i.e., triadic combinations).
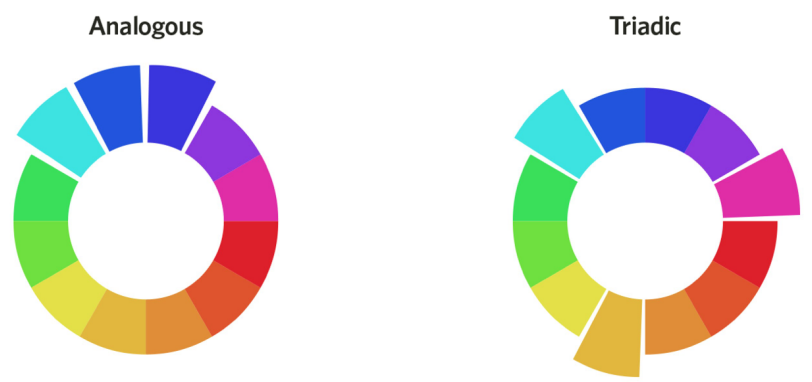

b. Keep it simple

i. Avoid overcrowding your social media graphics by:

1. Utilizing large, eye-catching graphics and illustrations

2. Limiting typeface to 2 font choices (one for the header/title and another for body text) and making sure the chosen fonts look good with one another

3. Sticking with 2-3 contrasting (or 'complimentary') colors

4. Using white space to contrast with a bold, colorful element

ii. Be mindful of every element you choose and make sure each one reflects the message you're trying to tell.

"Know when to put the mouse down!" - Red, Design Pickle graphic designer

c. Be consistent

i. Be sure to incorporate your brand's colors and fonts into your visual

ii. Every image that is part of the same campaign ought to include similar colors to reinforce the brand experience 


\section{Advertising using Instagram}

In this section, we will review the steps you should take when setting up paid ads on Instagram.

We assume you have read the previous sections that outline Instagram basics and that your ad text and images are IRB approved (depending on your IRB requirements). We highly recommend multiple people (including members of the groups you are planning to recruit) review the ad content to make sure the images are culturally appropriate for your target audience, and to ensure that your text and hashtags are clear, concise, relevant, and error-free.

\section{Step 0: Set your account to a "Professional Account"}

+ Go to "Settings"; Click on "Account"; Scroll down, and click "Switch to Professional Account" (Professional accounts are allowed to access business settings and features such as ads.)

+ Set category to "Educational Research Center" or a different category that represents your lab

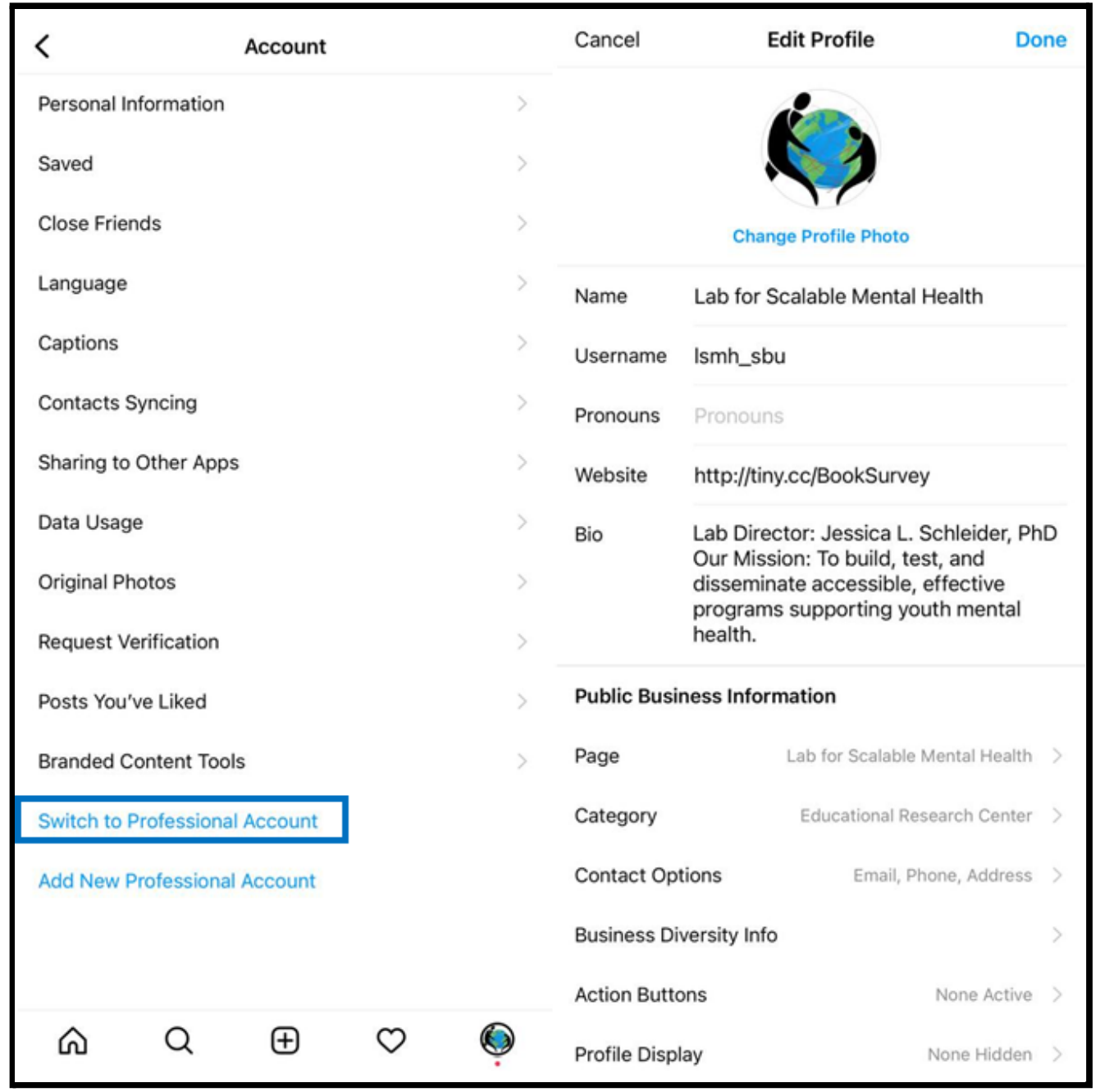




\section{Step 1: Post your ad}

+ Click the post button on Instagram

+ Select "Post"

+ Upload and edit your media

+ Write a caption and include relevant hashtags (including \#SocialMediaResearchNetwork, \#SMRN, \#SMRNetwork)

+ Click "Share"

\section{Step 2: Click "Boost" on your post}

+ Find the post on your account page

+ Click "Boost"

\section{Step 3: Select a Goal}

+ More Profile Visits: Clicking on your paid ad brings user to your Instagram profile

+ More Website Visits: Clicking on your paid ad brings user to a website of your choice

+ More Messages: Clicking on your paid ad brings user to your direct messages

$\begin{array}{lllll}\text { Cancel Goal } & \text { Next Cancel } & \text { Create Audience }\end{array}$

\section{Select a Goal}

What results would you like from this promotion?

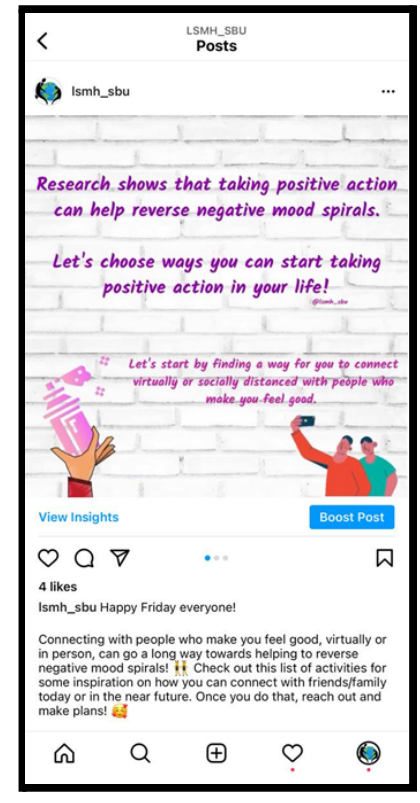


+ Interests: This allows you to target behavior and interests your audience should have (e.g. "Self-help groups for mental health", "LGBTQ community", and "Parenting"). NOTE: You cannot use interests to target anyone younger than 18 due to policy change as of October 2021.

+ Age \& Gender: This allows you to set age requirements (between 13 and 65) and gender (male and female).

\section{Step 5: Budget \& Duration}

+ Budget: Between $\$ 1$ and $\$ 1000$ a day (Pro Tip based on lab experience: use a small daily budget $\$ 20-\$ 50)$

+ Duration: Between 1 and 30 days (Pro Tip: keep ads on for at least 5-10 days)

+ Use about $10 \%$ of your ad budget for an initial test run (e.g. $\$ 10$ for 5 days $=\$ 50$ if your total ad budget is $\$ 500$ ) and the remainder in chunks. (Pro Tip: Never use your whole budget in one ad campaign so you have more control over recruitment rates and also so you can make changes to your campaign if needed)

\section{Step 6: Review \& Promote}

+ Confirm everything looks good and "Create Promotion"!

+ Ad approval takes 24-48 hours

\section{Step 7: Share with SMRN}

+ Message "Recruitment" channel on Slack with your Instagram handle and post description

+ Ask others to re-post to their Story

\section{Step 8: Insights and Next Steps}

$+\quad$ Keep an eye on Promotion Insights to know how well your ads are doing

+ Respond to comments publicly. Others may have similar questions or concerns. (Pro Tip: Some comments will be mean. Respond politely and professionally.)

+ Learn from each ad run and try to improve targeting for future ad runs using the same post.
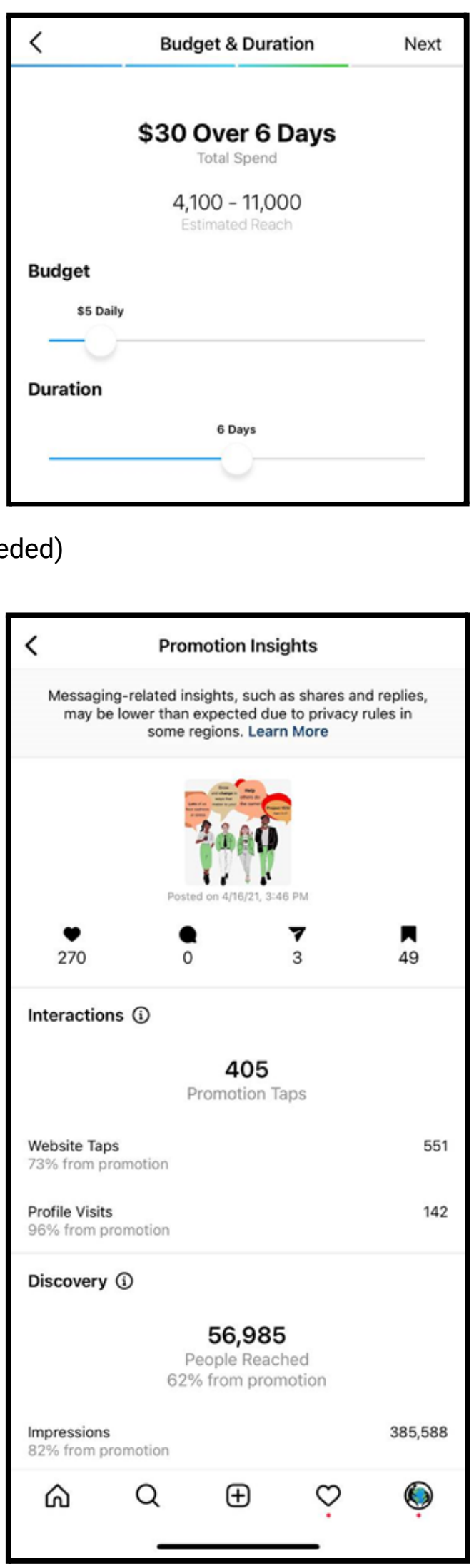
+ Only create a new post if your ad worked poorly (almost $0 \%$ of people clicked on your ad).

\section{Advertising using Facebook Ads Manager}

In this section, we will review the steps you should take when setting up paid ads on Facebook Ads. We assume you have read the previous sections that outline Instagram and Facebook basics and that your ad text and images are IRB approved (depending on your IRB requirements). We highly recommend multiple people review the ad content to make sure the images are culturally appropriate for your target audience and your text and hashtags are clear, concise, and relevant.

\section{Step 0a: Create a "Business Manager"}

+ Go to business.facebook.com

+ Set up the manager account

+ Add all users that need access

\section{Step 0b: Create an "Ad Account"}

+ Go to your business manager settings page

+ Create a new "Ad Account" under the "Accounts" section for your research group

\section{Step 0c: Create a "Facebook Pixel"}

+ Go to your business manager settings page

+ Create a new "Pixel" under the "Data Sources" section for your research group

+ Link your "Pixel" to your website domain

+ Note: If you don't own your website domain (e.g. the university or Qualtrics does), you should not create a Facebook Pixel. This will limit you to the type of metrics and targeting campaigns you can use.

\section{Step 1: Create a "Campaign"}

+ Go to your ads manager page

+ Create a new "Campaign" for each research study

+ Campaign Objective: Conversions OR Traffic.

+ Conversions allow you to track very specific events using your Pixel (e.g. clicking on your survey link or submitting a contact form).

+ Traffic allows you to track people that reach your website by clicking the ad. If you don't have a Pixel, this is a great alternative.

+ [Optional] Set a campaign spending limit. (Pro Tip: Never use your whole budget in one ad campaign)

+ [Optional] Turn on "Campaign Budget Optimization" and set a daily budget. (Pro Tip: use a small daily budget $\$ 20-\$ 50$ ) 


\section{Step 2: Set up your "Ad Set"}

+ Set up and link your Conversion event (if applicable).

+ [Optional] Turn on "Dynamic Creative". This enables Facebook to optimize your ads by automatically selecting different creatives (e.g. images, headlines, captions that you have defined) that work best for specific individuals.

+ Audience: Set up your target audience.

+ Location: This allows you to set up geographic targets as broad or narrow as you want (e.g. United States or 10-mile radius around Stony Brook University).

+ Age: You can set your age range from 13 to $65+$ years.

+ Gender: This allows you to select your target gender (all, men, or women).

+ Detailed Targeting: This allows you to select demographics, interests, and behaviors that meet your criteria (e.g. "Self-help groups for mental health", "LGBTQ community", and "Parenting"). Also, this allows you to exclude targeting metrics. NOTE: You cannot use detailed targeting to target anyone younger than 18.

+ Lanquages: This allows you to target people by language (e.g. English (all), English (US), and/or Spanish)

+ Placement: This allows you to decide where you want ads to show up (e.g. Facebook Messenger, Facebook News, and/or Instagram Stories).

\section{Step 3: Set up your "Ad"}

+ Identity: Choose your Facebook page and Instagram account (if applicable). If you don't see your page and account, go to the business manager settings to connect your Facebook Page and Instagram Account to your business.

+ Ad Setup: Select an existing post or create a new ad (and select an ad format).

+ Ad Creative: Your ad media, text, and destination can be set up here! (Pro Tip: Use the "Display Link" option to display your lab website regardless of where the survey is hosted.)

+ Language: Translate your own ad or let Facebook do it automatically. (Pro Tip: Translate your own ads! This allows you to select different media for each language as well.)

\section{Step 4: Publish}

+ Review and "Publish" your ad!

+ Ad approval takes 24-48 hours

\section{Step 5: Share with SMRN}

+ Message "Recruitment" channel on Slack with your Instagram handle/Facebook page and post description

+ Ask others to share the post with their followers 


\section{Step 6: Insights and Next Steps}

+ Keep an eye on Ad and Campaign charts

+ Respond to comments publicly. Others may have similar questions or concerns. (Pro Tip: Some comments will be mean. Respond politely and professionally.)

+ Edit and republish ads as needed. 


\section{SMRN Specific Suggestions}

In this section, we will review the recommended steps for SMRN. We can leverage all of our networks to increase participant recruitment, science communication, and outreach for the different aspects of psychology research we do. We hope everyone can work together to build this research network.

\section{Posting}

- When you post, please include one or more of the following hashtags

○ \#SMRN \#SMRNetwork \#SocialMediaResearchNetwork

○ This way when people click on the hashtag they will be brought to all other SMRN posts and they'll be able to interact with/follow labs in our community!

- Aim to post at least once a week to start out and work your way up to two or three times per week.

- One of the goals of the SMRN is to help everyone create and grow their social media presences; in order to do this, some work is required on your end (posting)!

\section{Interacting with SMRN members on social media}

- We strongly encourage reposting other SMRN members' content! This can range from recruitment ads, science communication and community outreach to every day posts.

- If you're planning to go Live to discuss your research or anything else, let the SMRN know via Slack, that way we can join in on our Lives and even go Live together! 